This is a post-peer-review, pre-copyedit version of an article published in The Spanish Journal of Psychology. The final authenticated version is available online at: https://doi.org/10.1017/SJP.2020.42

\title{
How does the Leader's Centrality affect Team Performance Assessment? Testing the Role of Leader's Satisfaction
}

Marta Pereira Alves ${ }^{1}$ http://orcid.org/0000-0002-8074-7168, Isabel Dórdio Dimas ${ }^{2}$ https://orcid.org/0000-0003-4481-2644, and Paulo Renato Lourenço ${ }^{2}$ https://orcid.org/0000-

$\underline{0003-1405-3835}$

\section{NECE-UBI, Universidade da Beira Interior, Portugal \\ 2 CeBER, Universidade de Coimbra, Portugal}

\section{Conflicts of Interest: None}

Funding Statement: This work has been supported by National Funds through FCT -

Fundação para a Ciência e a Tecnologia, I.P. (UIDB/04630/2020, UIDB/05037/2020).

Correspondence concerning this article should be addressed to Marta Pereira Alves. Research Center in Business Sciences (NECE-UBI), University of Beira Interior, Rua Marquês d'Ávila e Bolama, 6201-001, Covilhã (Portugal).E-mail: mpalves@ubi.pt

\section{How to cite this article:}

Alves, M. P., Dimas, I. D., \& Lourenço, P. R. (2020). How does the leader's centrality affect team performance assessment? Testing the role of leader's satisfaction. The Spanish Journal of Psychology, 23. EXX. http://doi.org/XXX 


\begin{abstract}
The study aims to test how the association between leader's centrality (outdegree and betweenness) in the group network, considering both workflow and friendship ties between leader and members, and the perception of team performance is mediated by the leader's satisfaction with the team. The research included a total of 74 formal leaders of organizational teams from several organizations. Total, direct and indirect effects were calculated through the estimation of an OLS regression-based mediation model, controlling for team size. Results revealed that only leader's outdegree and betweenness centrality in the team friendship network positively predicted the leader's perception of team performance. In contrast to the predictions, a significant negative indirect effect of outdegree centrality of the leader within the team workflow network on the evaluation of group performance through leader's satisfaction was observed. Also, both leader's outdegree and betweenness centrality levels in the friendship network were shown to have a positive effect on leader assessment of team performance through leader's satisfaction with the team. Overall, findings point to the negative effects of the leader's centrality in workflow team network and the positive effects of leader's centrality in the friendship team network on his/her attitudes toward the team. The effects of the more or less central position of the leader within each of the group networks are discussed.
\end{abstract}

Keywords: friendship network, leader's centrality, leader's satisfaction, team performance assessment, workflow network 
The interest in applying social network analysis to the study of leadership is widely recognized (Balkundi \& Kilduff, 2006; Carter et al., 2015; Hoppe \& Reinelt, 2010; Park et al., 2020). It is commonly agreed that the social network approach to leadership highlights the relational context where leaders are embedded, which could be defined by the relative position occupied by the leader within a social system and by the formal and informal ties established between the leader and each one of the actors of a given network. Hence, patterns of relationships among individuals in teams can be represented by social networks where a set of actors is linked by a certain type of ties.

In the present study, a team is considered as a complex adaptive system (CAS), i.e., it is embedded in organizations and presents complex and continuum dynamic adaptive behavior and is dependent on its history and also on its anticipated future (Arrow et al., 2000; RamosVillagrasa et al., 2018). Following complexity leadership theory, team leadership, which is the focus of our study, is conceived as an element of that CAS (Uhl-Bien \& Marion, 2011). According to the authors, embedded in complex networks and through the development of intersubjective interactions with their followers/subordinates, leaders co-evolve, creating a (jointly) co-constructed reality. Thus, the team is not an externality for the leader, an objective reality that the leader can control. Therefore, it will be expected that the leader's perception of the pattern of relational ties maintained with other team members may influence the leader's attitudes towards group outcomes. Accordingly, the purpose of this study is to analyze how leader's relative position in the workgroup network is associated with his/her perception of team performance, and how this relation could be explained by the satisfaction level of the leader with his/her own team. The literature highlights the presence of rater bias in performance assessment in the organizational context due to subjective and contextual factors which could affect it (Campbell \& Wiernik, 2015). As a result, it is expectable that leader ratings tend to be susceptible to the leader's own attitudes towards the team. In line with this, we assume that the level of satisfaction of the leader with the group will mediate the relation between leader's centrality in the team social network and the appraisal of team performance, as the leader's attitudes toward the team might be influenced by the location of the leaders within the network of ties they maintain with the other team members.

In summary, the main objective of this research is to analyze if the relative position of the leader, assessed by leader's centrality in both workflow and friendship group networks, affects the leader's perception of team performance, and if this association could be explained by the leader's satisfaction with the team. The study brings important contributions for the study of leadership in teams. First, it is in line with the call made by Uhl-Bien and Marion (2011), 
who state that complexity leadership research would benefit from the development of a variety of empirical studies, including, among other approaches, network analysis studies. Second, two team social networks are analyzed: The workflow and friendship networks. The flow of work between employees forms a structure of task-related interdependencies (e.g., information, materials) usually influenced by the division of labor in terms of exchanging inputs and outputs, and the friendship network constitutes a more flexible pattern of ties (e.g., mutual liking) which are more discretionary while depending more on personal choices (Mehra et al., 2001). Leadership behaviors toward team members are commonly distinguished as task- and relationship-oriented (Judge et al., 2004; Tabernero et al., 2009), but literature about the leader's centrality within team networks suggests that research usually studies task-related ties and socioemotional relations separately (Carter et al., 2015). The first dimension usually involves instrumental relations between leader and members, based on goal and task-oriented behaviors (e.g., task assignment, activities coordination, performance evaluation). The relational dimension of leadership consists of expressive relations between leader and members, established in socioemotional and supportive behaviors, like having friendly and approachable attitudes toward team members. Finally, the study also contributes to the social network analysis approach since two different centrality indexes are considered: Degree centrality and betweenness centrality. In fact, if degree centrality is relatively commonly studied to measure how central a leader is in the team, the same is not true for betweenness centrality; this is recognized as a promising area in the field of team research from a social network perspective due to the observed mixed effects on leader and team outcomes (Park et al., 2020). Therefore, this study can shed some light on the explanation of the effects of leader's centrality, both degree and betweenness, on his/her attitudes and perceptions about the team, considering both workflow and friendship ties maintained with team members.

\section{Leader's Centrality and Team Performance}

The level of centrality of the leader is associated with either beneficial or detrimental effects on team performance, depending on the centrality indicator, the type of network and performance measures considered. In general, the empirical evidence that the leader's centrality within the team is positively associated with positive team and individual outcomes is shown by both meta-analytic (e.g., Balkundi \& Harrison, 2006; Mullen et al., 1991) and literature review studies (e.g., Carter et al., 2015). In particular, Balkundi and Harrison (2006) presented both supportive and opposing arguments of the hypothesis predicting a positive association between formal leader's incoming ties in the team's instrumental social network and team 
performance. The results of this meta-analytic study concluded that leader centrality was positively related to team task performance. Accordingly, leader's centrality in informal team networks is usually associated with strategic positions in terms of providing resources, regulating the information flow and giving directions to team members towards attaining common goals. Research has demonstrated a positive association between the degree centrality of the leader in the team network and team performance when assessed by different objective measures, such as external supervisors' ratings (Balkundi et al., 2011) and customer loyalty (Mehra et al., 2006). Another study revealed a positive effect of leader's degree centrality in the team task-advice network, which was not found in the friendship network, on enhancing the desirable consequences of team cohesion on team performance when rated by group members (Nootjarat et al., 2015). In contrast, team members' intention to quit the team was higher in teams where the leader had a higher level of betweenness centrality degree, i.e., when he/she was more central in terms of bridging ties between unconnected subordinates (Balkundi et al., 2009).

\section{Leader's Degree Centrality and Team Performance}

Most studies in the literature operationalize leader's centrality within teams as degree centrality because dyadic ties between team leader and members are treated as undirected or symmetric links (Carter et al., 2015; Mullen et al., 1991). When studies use directed data, two indexes of degree centrality can be calculated: the indegree centrality indicator (which depends on the number of received ties in asymmetric networks) and the outdegree centrality index.

In this study, we use the outdegree centrality index (i.e., the number of outgoing direct connections the leader maintains with team members) because we intend to analyze how the level of leader's centrality in the network in terms of providing access to relevant information, which is considered as a task-oriented leadership behaviour (Behrendt et al., 2017), could affect the perception of team performance. The level of outdegree centrality within a team is usually defined as an indicator of status in the network, i.e., how influential the individual is recognized as being in the group (Sauer \& Kauffeld, 2015). If a leader has a high level of outdegree centrality in the friendship network, it means that the leader considers a high number of team members as friends, which might be interpreted as an indicator of "gregariousness" or "expansiveness" of the individual in the network (Borgatti et al., 2013). Friendship networks

are commonly established on reciprocal ties and, hence, social network research frequently considers the structure of friendship relationships as a symmetric network (e.g., Mehra et al., 2006; Mehra et al., 2001; Wang et al., 2017). Considering the same social network measure 
adopted to assess workflow ties, leader's centrality would be also operationalized based on the outgoing ties between the leader and the other team members (e.g., with whom the leaders consider they have a friendship relation).

Based on the literature presented above, we expect that perceived team performance will be positively predicted by leader's degree centrality (i.e., an expansiveness indicator) in the team network both in terms of giving task-related information (e.g., Balkundi et al., 2011; Nootjarat et al., 2015) and maintaining a close relationship with subordinates (e.g., Mehra et al., 2006).

Hypothesis 1a: The leader's outdegree centrality in the team in the workflow network positively predicts the leader's perception of team performance.

Hypothesis $1 \mathrm{~b}$ : The leader's outdegree centrality in the team in the friendship network positively predicts the leader's perception of team performance.

\section{Leader's Betweenness Centrality and Team Performance}

Most research about leader's centrality in team networks is based on degree centrality index. The betweenness centrality level is typically considered as an indicator of potential for controlling the flow and coordinating otherwise separate parts of the network (Borgatti et al., 2013; Knoke \& Yang, 2008; Wasserman \& Faust, 1994). When leader's centrality is assessed by betweenness centrality, the whole social structure of the group is analyzed and the relative position of the leader within the team is contingent upon subordinates' perceptions.

In our study, we expect that the leader's assessment of team performance could be more favorable if the leader brokers important task-related information more extensively between different team members as this central position has been associated with the potential for controlling and maintaining communication flow (Mullen et al., 1991). Similarly, when the leaders intercept many friendship relationships between pairs of team members they are in a favorable position of mediating the interaction between members who are not affectively close to each other.

Despite the lack of empirical studies about the possible influence of leaders' betweenness centrality in team networks on team performance, the literature suggests that the leader's potential for bridging relationships between disconnected team members is associated with positive outcomes (Mullen et al., 1991). Therefore, we predict that the level of betweenness centrality (i.e., a brokerage indicator) of the leader in the team network positively predicts the leader's evaluation of team performance, both in task-related and private social networks. 
Hypothesis 2a: The leader's betweenness centrality in the team in the workflow network positively predicts the leader's perception of team performance.

Hypothesis 2b: The leader's betweenness centrality in the team, in terms of the friendship network, positively predicts the leader's perception of team performance.

\section{Mediating Role of Leader Satisfaction with the Team}

The positive effect of a more central position of the leader within a group network on team performance is usually found when team performance is assessed by objective measures. The literature suggests that when the evaluation of individual or group outcomes is made by formal leaders or followers embedded within teams, the judgments may be influenced by the perspective given by the relative position occupied in the team's overall social structure. In teams with a high-central leader, the team members who were closer to their leader, in terms of strength of task-advice ties, gave higher rates to team performance (Nootjarat et al., 2015). Similarly, Wang et al. (2017), found that team members' perception of leadership effectiveness was more strongly affected by the strength of affective leader-member tie when team members were more central (in terms of indegree centrality) in the friendship and work-related advice team networks. Based on these results, we also predict that the position of the leader in the team network will influence the judgment of the team performance so that the more centrally the leader is located, the more favorable the assessment of group performance may be.

There has been evidence that both degree and betweenness centrality of a group member in the communication network are positively associated with the individual satisfaction level (e.g., Flap \& Völker, 2001; Mullen et al., 1991). A leader who is central in the team network could control the flow of information (personal and task-related) and may promote coordination between different parts of the network. The literature suggests that having a central position in the group network is congruent with both leaders' and followers' expectations and attributions about what leadership behaviors and attitudes should be, and this perceived cognitive consonance (cf. Festinger, 1962) might promote positive attitudes of the leader toward the team. Since the early studies of Bavelas, Leavitt and Shaw in the 1950s, there has been empirical evidence that the probability of an individual emerging as an informal leader within the group is associated with a more centralized position in the communication network (Mullen et al., 1991). More recently, other studies found that leaders who were more central within team taskadvice network were also perceived by followers as showing more leadership characteristics and behaviors (Chiu et al., 2017) and as being more charismatic (Balkundi et al., 2011). Also, leader reputation among subordinates within their own group is positively explained by the 
leader's degree centrality in the friendship network (Mehra et al., 2006) and a strong leader self-identity positively predicted higher levels of degree and betweenness centrality in friendship and advice team networks, respectively (Kwok et al., 2018). Research also suggest that team members who have secure attachment styles (i.e., who tend to seek interdependent, supportive and trustworthy interpersonal relationships) are more likely to emerge as leaders than insecurely attached team members (i.e., who tend avoid social interaction and emotional closeness with other people) (Berson et al., 2006).

Occupying a central position could enhance the leader's sense of control over the information exchange flow between team members and, consequently, might positively determine the perceived efficiency of the team through the increase in satisfaction. A central position within a group gives the leader the perception of power while providing and regulating resources with an important impact on the functioning and performance of the team. Leaders' beliefs of self-efficacy are also positively associated with leaders' positive emotions (Carleton et al., 2018). Research suggests that workplace friendships promote high-quality relationships between colleagues, based on exchanges of support, trust and recognition between team members (Tse \& Dasborough, 2008). Venkataramani et al. (2016) found that when leaders have a central position as a friend within the team (in terms of incoming ties), the most connected subordinates in the team workflow network also have a higher tendency to contribute to task improvement through voicing suggestions (e.g., giving recommendations about ways to improve work in the team). Accordingly, leaders who occupy a central location in the friendship team network may have the perception of more instrumental and emotional support within their own group. The leader's positive attitudes toward the team would in turn influence and interfere with the judgment of team performance. Although some conceptual models of team effectiveness conceptualize team satisfaction as a criterion of team effectiveness (e.g., Hackman, 1987), previous research supported the role of satisfaction as a mediating variable between team inputs and team performance (e.g., Kong et al., 2015; Li et al., 2009; van de Voorde et al., 2014).

In conclusion, the more central leaders are in terms of information sharing and friendship ties, the more positively they would evaluate the performance of the team because they would be more satisfied to be part of that group. Thus, the following two mediating hypotheses are presented.

Hypothesis 3: The leader's satisfaction with the team positively mediates the association between the level of leader's outdegree centrality in the team, in terms of the workflow (Hypothesis 3a) and friendship (Hypothesis 3b) networks, and the perception of team 
performance.

Hypothesis 4: The leader's satisfaction with the team positively mediates the association between the level of leader's betweenness centrality in the team, in terms of the workflow (Hypothesis 4a) and friendship (Hypothesis 4b) networks, and the perception of team performance.

\section{Method}

\section{Participants}

Data were collected from a sample of 74 formal leaders of organizational teams and 318 team members from 31 Portuguese organizations from different activity areas, namely industry (25.8\%), health institutions (19.3\%), information and communication technology (16.2\%), commerce (12.9\%), consultancy (13.0\%), transportation and distribution (9.6\%), and construction $(3.2 \%)$. The majority of the leaders were male $(81.1 \%)$ and the average age of was 42.78 years $(S D=8.24)$. Regarding their educational level, only $1.4 \%$ had less than the basic schooling (i.e., nine years of education), $27.0 \%$ had between nine and twelve years of education, $51.3 \%$ were graduated, and $20.3 \%$ had a postgraduate degree. Average organizational tenure was $11.24(S D=8.92)$ and average team tenure was 5.10 years $(S D=$ 4.69). The sample included leaders of department/service management teams (22.4\%), commercial and marketing teams (20.9\%), project teams (16.4\%), human resources management teams $(13.5 \%)$, quality control teams (10.4\%), financial management teams (10.4\%), and top management teams (6.0\%). Most team members were male (56.5\%) with an average age of $38.40(S D=9.43)$. Average organizational tenure was 10.96 years $(S D=8.82)$ and average team tenure was 4.44 years $(S D=4.18)$. Team size ranged from three to ten members $(M=5.30 ; S D=1.89)$.

Although teams in our sample were from different functional areas, all of them performed non-routine tasks, i.e., tasks that require problem-solving, have just a small set of standardized procedures, and have a relatively high degree of uncertainty (O'Reilly et al., 1998). All the team leaders were formal leaders, being externally and internally recognized as the main person responsible for the team. Since they interact regularly with team members, they are recognized by the organization as being part of the team. Therefore, according to the taxonomy proposed by Morgeson et al. (2010, the leaders of our study were internal and formal leaders. 


\section{Measures}

\section{Leader's Centrality}

This study focuses on individual-level constructs because only the centrality level of the leader in workflow and friendship networks was assessed through two indexes, based on Freeman's approach (Freeman, 1979): Degree and betweenness centrality. Data were collected from all the members of each group. Responses were given on a 7-point scale from 1 (never) to 7 (always) regarding four questions assessing the frequency of the ties between each pair of colleagues of the same team, including the leader (see Appendix). For assessing the workflow ties established between the leader and the other team members, one question was considered (Alves \& Lourenço, 2017) and to account for the friendship ties maintained by the leader with the group members, three questions were included (Alves et al., 2013). The average of the individual scores of the three items was calculated before centrality measures were computed for each leader. When assessing personal relationships by social network analysis questionnaire, some authors (e.g., Borgatti et al., 2013; Knoke \& Yang, 2008) argue that an informant bias may emerge in the perception of what might be interpreted as close or distant relations (e.g., a friend). In order to prevent this methodological issue, the word "friend" was not used in the questionnaire and three different questions were used to assess the frequency of specific behaviors. Directed and dichotomous data were considered, given that each tie was present when the individual score was equal or higher than 4 (sometimes). For directed (or asymmetric) data, the degree centrality of each individual in the network can be defined by the incoming or outcoming ties. In this study, only outdegree centrality of the leader is considered and it is calculated as the number of team members who are chosen by the leader, in terms of workflow and friendship network. Betweenness centrality is a measure of how often an individual mediates the relations between dyads that are not connected by a direct path (Knoke $\&$ Yang, 2008). The level of betweenness centrality of the leader is calculated as the proportion of times the leader lies along the shortest path connecting any pair of team members, considering all the shortest paths that connect them (Borgatti et al., 2013). Therefore, responses of all the members of each team needed to be considered to compute the betweenness centrality of the leader. Raw scores for centrality measures were calculated using the UCINET 6 software program (Borgatti et al., 2002).

\section{Perception of Team Performance}

To measure the leader perception of team performance, we used the Group Performance Scale developed by Lourenço et al. (2014), a one-dimensional scale that is composed of ten 
items that measure the leaders' perception of team performance outcomes and goal achievement regarding different issues related to the quality and quantity of work produced by the team (see Appendix). Statements are evaluated on a Likert-type, 10-point scale ranging from 1 (poor) to 10 (excellent). In order to test the unidimensionality of perceived team performance, confirmatory factor analysis was conducted using the maximum likelihood procedure. Covariances were added between two error pairs of items with related content (Items 2 and 4; Items 6 and 9) and two error pairs of consecutive items (Items 6 and 7; Items 7 and 8). The results revealed an acceptable model fit, $\chi^{2}(31)=58.65, p<.01 ; \chi^{2} / \mathrm{gl}=1.96 ; \mathrm{CFI}=.95 ; \mathrm{GFI}=$ $.86 ; \mathrm{RMSEA}=.11, p=.002$.

\section{Leader's Satisfaction with the Team}

To measure the level of satisfaction of the leader with the team, we used the Workgroup Satisfaction Scale developed by Lourenço and colleagues (2014). This is a one-dimensional scale that is composed of seven items that measure the level of satisfaction with different aspects related to the task and the affective system of the team (see Appendix). In the present study, one of the items was not considered since it is concerned with the level of satisfaction of the respondent with the way the leader organizes and coordinates the team's activities. Statements are evaluated on a Likert-type, 7-point scale ranging from 1 (totally dissatisfied) to 7 (totally satisfied). The unidimensionality of the measure was tested through confirmatory analysis (maximum likelihood procedure). Concerning overall model fit analyses and after adding covariances between one error pair involving content-related items (Items 1 and 6), the results indicated a good model fit, $\chi^{2}(8)=15.70, p=.05 ; \chi^{2} / \mathrm{gl}=1.89 ; \mathrm{CFI}=.98 ; \mathrm{GFI}=.93$; RMSEA $=.12, p=.05$.

\section{Control Variables}

Team size was controlled for all the analysis. First, because the literature mentions the association between team size and group participation in information exchange and interpersonal interaction (e.g., Curral et al., 2001), and group outcomes (e.g., Campion et al., 1993; Haleblian \& Finkelstein, 1993). Second, individual centrality measures are affected by the number of actors of the network (Borgatti et al., 2013; Knoke \& Yang, 2008).

\section{Procedure}

The organizations were first contacted by letter in order to assess their availability to participate in the research. Then we met the organization or team representatives to better explain the objectives and procedures of the study and to define a plan of action for data 
collection, namely the selection of the teams to survey. Following Cohen and Bailey's (1997) definition of a group, teams had to meet the following criteria: (a) teams must be constituted by at least three members; (b) who are perceived by themselves and others as a team; and (c) who interact regularly, in an interdependent way, to accomplish a common goal. Social network questions were anonymously filled in at the same time by each team member in the organization setting, including the leaders, and a codification system was created to guarantee identity protection of respondents (i.e., a letter was assigned to each team member before questionnaire completion and only participants knew the correspondence between each person and the code). Both satisfaction with the team and group performance questionnaires were answered by team leaders. Before data collection, meetings were held between the research team and representatives of the organizations in order to ensure that the criteria for including leaders in the sample were met. Additionally, during data collection, a member of the research team was present to ensure the standardization of data collection procedures and conditions. Informed consent allowing research participation was required from team members, organization representatives and researchers.

\section{Design and Statistical Analysis}

The present study was correlational and cross-sectional. In the first model, the predictors were the leader's outdegree centrality for both the work-related workflow network and the friendship network and the criterion was the leader's perception of group performance. In the second model, the betweenness centrality of the leader in both of the networks considered were entered as predictors and the perception of group performance as criterion. For both models, the proposed mediator was the leader's satisfaction with the team. All the hypotheses were tested with hierarchical multiple regression analysis. A set of OLS regression-based mediation models were estimated to calculate total, direct and indirect effects. Team size was considered as covariate in all the multivariate analyses. Mediation hypotheses were tested through mediation bootstrapping analysis, generated by PROCESS macro for SPSS (Version 3.3), following the orientations of Preacher and Hayes (2008) and Hayes (2018).

\section{Results}

Means and standard deviations for each scale and bivariate correlations among all the study's variables are presented in Table 1 . Team size (control variable) is significantly and positively associated with all the network centrality indicators. 


\section{<Insert Table 1 Here >}

\section{Leader's Outdegree Centrality as Predictor}

To test the total effects of leader's outdegree centrality, in terms of workflow and friendship networks (Hypothesis 1), simultaneous regression analyses were conducted and the effects of the predictors were adjusted for the effect of team size (see Table 2, Total effects). Only leader's centrality in the friendship network positively predicted the perception of team performance, $b=0.14, S E=0.07, p<.05$. To examine the mediational effects of leader's outdegree centrality, in terms of both workflow and friendship networks, hierarchical regression models were analyzed, controlling for team size. This mediational model is represented in Figure 1.

\section{< Insert Figure 1 Here>}

To analyze the direct pathways between the variables of the model, perception of team performance was regressed on the predictors, and then leader satisfaction with the team (mediator) was entered into the model (see Table 2, Direct effects). The perception of team performance was only positively predicted by the leader satisfaction with the team, $b=0.41$, $S E=0.14, p<.01$, since none of the leader's outdegree centrality variables revealed a significant association with the leader's appraisal of team performance, $p>.05$. However, we point out the fact that the total effect of leader's outdegree centrality in the friendship network on the perception of team performance was significant and become not significant after controlling for the mediator, $p>.05$ (see Table 2) which means that a total mediation of leader's satisfaction with the team was obtained. Finally, the direct pathways between each of the predictors and the mediator were analyzed (see Table 3). The results indicate that leader's outdegree centrality in both workflow network, $b=-0.12, S E=0.06, p<.05$, and friendship network, $b=0.12, S E=0.05, p<.05$, predicted leader satisfaction with the team. Although not previously foreseen, the workflow network centrality level of the leader negatively predicted the level of satisfaction with the team. Contrastingly, the level of centrality of the leader in the friendship network positively predicted the satisfaction level of the leader with the team.

\section{<Insert Table 2 Here> <Insert Table 3 Here>}

\section{Leader's Betweenness Centrality as Predictor}

To analyze the total effects of leader's betweenness centrality in terms of workflow and friendship networks (Hypothesis 2), regression analyses were calculated, controlling for team size (see Table 4, Total effects). Once again, only leader's centrality in the friendship network 
was shown to be a significant predictor of the perception of team performance, $b=0.12, S E=$ $0.05, p<.05$. To examine the direct pathways between predictors, mediator and criterion represented in the mediation model present in Figure 2, the dependent variable was regressed on the predictors, and then the hypothesized mediator was introduced into the model, controlling for team size.

\section{<Insert Figure 2 Here>}

In Table 4 (Direct effects), leader perception of team performance is regressed on the betweenness centrality of the leader in the workflow and friendship networks, controlling for the level of satisfaction with the team. The positive association between leader's betweenness centrality in the friendship network and his/her perception of team performance almost reached statistical significance, $b=0.09, S E=0.05, p=.06$. The effect of leader's betweenness centrality in the friendship on the evaluation of team performance did not remain significant after entering the mediator into the model. These results suggest once again a total mediation of the leader's satisfaction with the team in the association between the level of betweenness centrality in terms of friendship ties and the perception of team performance. Leader's betweenness centrality in the workflow network was not a significant predictor, $p>.05$, and leader satisfaction with the team was positively related to perception of team performance, $b=$ $0.41, S E=0.13, p<.01$. Table 5 shows that the direct pathways between the predictors and the mediator were not significant. Neither leader's betweenness centrality in the workflow network nor leader's betweenness centrality in the friendship network was a significant predictor of the level of satisfaction with the team, $p>.05$. However, as is clearly pointed out in the literature (e.g., Preacher \& Hayes, 2008; Zhao et al., 2010), unlike the causal steps procedure, which required the significance of trajectories between predictor and mediator and between mediator and criterion as preconditions for mediation, from the perspective adopted for these analyses, the focus is placed on the magnitude and direction of the indirect effects that result from the product of these direct effects.

\section{<Insert Table 4 Here> \\ <Insert Table 5 Here>}

\section{Mediation of Leader's Satisfaction: Indirect Effects}

To test the mediational effects of leader satisfaction with the team on the relationship between leader's centrality measures and perception of team performance (Hypotheses 3 and 4), a resampling bootstrapping procedure and 50,000 samples were used for indirect confidence intervals (Hayes, 2018). The results presented in Table 6 revealed the following significant 
indirect effects of the leader's satisfaction with the team, considering team size as covariate:

1. A negative indirect effect in the relation between leader's outdegree centrality in the workflow network and perception of team performance, with a point estimate of $-0.05,95 \% \mathrm{CI}$ $[-0.13,-0.01]$.

2. A positive indirect effect between leader's outdegree centrality in the friendship network and perception of team performance, with a point estimate of $0.05,95 \% \mathrm{CI}[0.01,0.13]$.

3. A positive indirect effect between leader's betweenness centrality in the friendship network and perception of team performance, with a point estimate of $0.03,95 \%$ CI [0.01, 0.10]. Some authors admit that when an indirect effect is significant without the direct effects being so, it would be more reasonable to consider the presence of indirect effects instead of a mediation (Hayes, 2009).

\section{<Insert Table 6 Here>}

\section{Discussion}

The purpose of the present study was to examine the associations between the leader's level of centrality in the team social network and leader's perception of the performance of the team and to test the mediating role of leader's satisfaction in those relationships. In particular, outdegree and betweenness measures of leader's centrality were analyzed in both workflow (i.e., instrumental work-related ties) and friendship (i.e., emotional ties) team social networks. First, the results revealed the relevance of emotional ties between leader and members, as only the leader's centrality in the team friendship network, both degree and betweenness centrality, positively predicted the leader's perception of team performance. Thus, both Hypotheses $1 \mathrm{~b}$ and $2 \mathrm{~b}$ were supported. Contrastingly, Hypotheses $1 \mathrm{a}$ and $2 \mathrm{a}$ were not supported by the results since leader's centrality (both outdegree and betweenness centrality) in the team workflow network did not significantly predict the leader's perception of team performance. Indeed, even though there is evidence of a positive association between leader's centrality within workrelated networks and positive team and individual outcomes (Balkundi \& Harrison, 2006; Carter et al., 2015; Mullen et al., 1991), the literature also points to some possible different effects. Although Balkundi and Harrison (2006) have emphasized the positive effects of having a central leader in a team, the authors also recognize some possible drawbacks associated with leader's centrality in the group communication network in terms of receiving ties. These disadvantages, which could also be associated with a high number of outgoing ties, may be associated with the leader's inability to process and manage critical information for members' 
task accomplishment and, also, in maintaining a sufficient distant and critical position in relation to subordinates which could facilitate the recognition of a poor team performance, especially when formal leaders are recognized as being part of the group. Balkundi et al. (2009) found a negative association between the level of betweenness centrality of the leader in team advice network and team viability (i.e., team members' intention to quit their team). These results could, in part, be explained by the differences observed in the operationalization and assessment of team performance. The research about the impact of leader's centrality on team performance usually considers objective criteria or perceptive measures of external supervisors and team members in assessment of group outcomes. In most organizations, the leader is the main source of team performance ratings because they are the one that first receives and reviews the team outputs (Hackman, 1987). Notwithstanding the fact that the leader's evaluation has been consistently considered as one of the most common and valid sources of work performance ratings in organizations (Scullen et al., 2000; Viswesvaran et al., 1996), the perspective of the formal leader of the team has not been considered in evaluating team performance when the research purpose is to study the association between the leader's position in the team network and team outcomes. Therefore, the present study intended to assess if the leader's evaluation of the performance of the group could be explained by the more or less favorable attitudes of the leader toward the team. So, the level of satisfaction of the leader with the team was considered as a mediator between the centrality level of the leader within the team (workflow and friendship networks) and the assessment of group performance.

Regarding mediation hypotheses, the results showed distinct indirect effects. Both Hypothesis 3 and 4 were only partially supported, as we anticipated the presence of positive indirect effects of leader satisfaction with the team between leader's centrality (degree and betweenness) in both communication and friendship team social networks. First, and in contrast to our prediction (Hypothesis 3a), we observed a significant negative effect of leader's satisfaction in the association between workflow degree centrality of the leader and his/her evaluation of group performance. The more central the leader in the workflow network, the lower were the satisfaction levels that the leader showed regarding the team, which in turn led to a less positive evaluation of team performance. Second, leader satisfaction with the team did not mediate the association between leader intermediation level within the team workflow network and the leader evaluation of team performance (Hypothesis 4a). Even if the literature suggests that privileged access to information is recognized as a part of a leader's role (Balkundi et al., 2011) and a source of individual satisfaction (Flap \& Volker, 2001; Mullen et al., 1991), some authors also refer to the presence of negative effects of the leader's degree centrality in 
the workflow team network on the leader's attitudes. This could be explained by high workload and dependence of followers or by coordination failures between leader and members (Balkundi \& Harrison, 2006; Nootjarat et al., 2015). The teams which participated in the present study were mainly responsible for non-routine tasks, with some degree of uncertainty and ambiguity. Additionally, the leaders of these teams interact regularly with team members and are engaged in part of the team's task cycle, namely structuring and planning the team activities, monitoring and providing feedback, solving problems and supporting social climate (Morgeson et al., 2010. Therefore, in a centralized workflow network with these characteristics, team members could frequently rely on the leader, who in turn may feel overwhelmed in terms of information management within the group and less available to focus on the development and maintenance of relationships outside the group. These unpleasant conditions negatively affect leader's attitudes toward the team and, consequently, lead to a poor evaluation of team performance. In fact, the positive effect of a more central position of the leader on team performance is commonly observed when team performance is assessed by objective measures or external judgments (e.g., Balkundi et al., 2011; Mehra et al., 2006; Sauer \& Kauffeld, 2015). Thus, we can assume that when team performance is assessed by the internal leader of the team, this evaluation may be influenced by the perspective given by the leader's relative position within the group while affecting his/her attitudes and feelings about the team as whole.

Finally, outdegree centrality of the leader in the friendship network was shown to have a positive effect on leader attitudes toward the team and consequently on leader judgment of team performance (Hypothesis $3 b$ ). Thus, the results also highlight the existence of positive effects of the leader's centrality in the friendship team network on the leader's attitudes that could be explained by instrumental and emotional support and by close leader-member relationships (Balkundi \& Harrison, 2006; Nootjarat et al., 2015). Accordingly, the leader's central position in the group friendship network promotes a more trustworthy and proactive relationship between leader and employees (Venkataramani et al., 2016), which in turn may contribute positively to the leader's perception of a better team performance. Also, a more central leader, in terms of degree centrality, in the team friendship network is positively associated with both leader status among subordinates (Mehra et al., 2006) and leader role identity (Kwok et al., 2018). The cognitive consonance that come from the leader's perception of consistency between his/her attitudes and behavior and leader role expectations is psychologically comfortable (cf. Festinger, 1962) and could positively influence the leader's affective responses toward the team and, consequently, the evaluation of team performance. Although further research is needed, it can be supposed that similar mechanisms may explain 
the positive effect of the leader's satisfaction with the team in the relation between leader's betweenness centrality and the perception of team performance (Hypothesis $4 b$ ). A leader who occupies a bridging position between several pairs of team members can encourage friendship ties between unconnected team members, fostering more cohesive relationships within the group. This advantageous position of the leader could also explain the increase of his/her level of satisfaction with the team through the perception of social support, prestige among subordinates and control over team members' interactions.

The findings need to be considered in light of some weaknesses associated with the study's design and methodology. One of the limitations of the present study is its cross-sectional design with relatively small sample, which makes it impossible to draw conclusions about the empirical causality of the relationships between the variables under study. In particular, the direction of the relationship between the leader's satisfaction with the team and the leader's perception of team performance might be of a different nature. Indeed, although satisfaction has been studied as an antecedent of team performance (e.g., Kong et al., 2015), since it is expected that the affective response of the leaders towards the team will influence their disposition to work with the team and the way they analyze the team results, it is also possible that a team that is evaluated by its leader as good performers will increase his/her levels of satisfaction with the team. Future research should address these issues by controlling for the variable team performance assessed by objective indicators and/or implementing a longitudinal design. Since the satisfaction of the leader with the group influences his/her evaluation of the group's performance, in future studies which use perceptual measures of group performance by the leader, his/her attitudes toward the team should be controlled. Further studies could also consider different levels of analysis, for example including members' level of satisfaction with the team as a potential consequence of leader's centrality. Despite these methodological questions, the use of social networks analysis can be seen as a strength, since this approach conceptualized and operationalized ties between leader and team members using a different procedure with the collection of data occurring at the dyadic level.

Overall, findings draw attention to the presence of negative effects of the leader's degree centrality in workflow team network (a task-oriented leader's behavior) and the existence of positive effects of leader's centrality in the friendship team network (a relationship-oriented leader behavior). These current findings have important implications.

First, communication patterns in teams where leaders show a high level on ongoing ties with team members, in terms of giving information and materials, should be managed to prevent negative leader attitudes toward the team. In the context of teams who perform non-routine and 
complex tasks, central leader's satisfaction with the team could be very affected by uncertainty and overload work conditions. Previous research based on social exchange theory has shown that employees tend to reciprocate with positive behaviors such as organizational citizenship behaviors (Chiu \& Chen, 2005) or higher levels of task performance (Li et al., 2009) to benefit the team or organization when they feel satisfied with their team. Therefore, organizational managers should regularly monitor leader's satisfaction with the team in order to prevent negative consequences for both leaders and teams' performance.

Second, both objective and subjective measures should be considered to evaluate team performance, as friendship relationships between leader and team members may interfere with team judgments. When leaders are part of the team, the evaluation of their own group will probably be affected by perception biases, particularly if they occupy a central position regarding the emotional ties maintained with team members. Based on social identity approach, leaders may recognize in themselves the more salient and positive characteristics of the team and then evaluate other ingroup members favorably as they also represent those prototypical group features (Hogg, 1993). Indeed, there is empirical evidence that group identification and favorable attitudes toward the group as a whole are positively associated with friendship relationships between team members (Hogg \& Hains, 1998). Accordingly, based on a cognitive network perspective of leadership, presented and discussed by Balkundi and Kilduff (2006), helping leaders and managers to build an accurate representation of team network ties involving workflow and friendship relationships could be an important tool to efficiently manage the social relations with followers, and also between team members, and prevent cognitive distortions in information processing about the team, particularly in the perception and appraisal of team outcomes. 


\section{References}

<REFJ> Alves, M. P., \& Lourenço, P. R. (2017). Workgroup interdependence assessment: Groupreferent scales and social network analysis. Testing, Psychometrics, Methodology in Applied Psychology, 24(1), 23-44. http://doi.org/10.4473/TPM24.1.2

$<$ REFJ > Alves, M. P. , Lourenço, P. R., \& Miguez, J. (2013). How to measure socioemotional ties in workgroups? Validation of Workgroup Socioaffective Interdependence Scale. Procedia Social and Behavioral Sciences, 84, 1084-1089. http://doi.org/10.1016/j.sbspro.2013.06.704<REFJ> Arrow, H., McGrath, J. E., \& Berdahl, J. L. (2000). Small groups as complex systems: Formation, coordination, development, and adaptation. Sage Publications. http://doi.org/10.4135/9781452204666

<REFJ> Balkundi, P., Barsness, Z., \& Michael, J. H. (2009). Unlocking the influence of leadership network structures on team conflict and viability. Small Group Research, 40(3), 301-322. http://doi.org/10.1177/1046496409333404

$<$ REFJ > Balkundi, P., \& Harrison, D. A. (2006). Ties, leaders, and time in teams: Strong inference about network structure's effects on team viability and performance. Academy of Management Journal, 49(1), 49-68. http://doi.org/10.2307/20159745

$<$ REFJ> Balkundi, P., \& Kilduff, M. (2006). The ties that lead: A social network approach to leadership. The Leadership Quarterly, 17(4), 419-439. http://doi.org/10.1016/j.leaqua.2006.01.001

$<$ REFJ $>$ Balkundi, P., Kilduff, M., \& Harrison, D. A. (2011). Centrality and charisma: Comparing how leader networks and attributions affect team performance. Journal of Applied Psychology, 96(6), 1209-1222. http://doi.org/10.1037/a0024890

$<$ REFJ > Berson, Y., Dan, O., \& Yammarino, F. J. (2006). Attachment style and individual differences in leadership perceptions and emergence. The Journal of Social Psychology, 146(2), 165-182. http://doi.org/10.3200/SOCP.146.2.165-182

$<$ REFJ> Behrendt, P., Matz, S., \& Göritz, A. S. (2017). An integrative model of leadership behavior. The Leadership Quarterly, 28(1), 229-244. http://doi.org/10.1016/j.leaqua.2016.08.002

$<$ REFJ> Borgatti, S. P., Everett, M. G., \& Johnson, J. C. (2013). Analyzing social networks. Sage Publications.

$<$ REFJ> Borgatti, S. P., Everett, M. G., \& Freeman, L. C. (2002). UCINET for Windows: Software for social network analysis. Analytic Technologies.

<REFJ > Campbell, J. P., \& Wiernik, B. M. (2015). The modeling and assessment of work performance. Annual Review of Organizational Psychology and Organizational Behavior, 2, 47-74. https://doi.org/10.1146/annurev-orgpsych-032414-111427

$<$ REFJ> Campion, M. A., Medsker, G. J., \& Higgs, A. C. (1993). Relations between work group characteristics and effectiveness: Implications for designing effective work groups. Personnel Psychology, 46(4), 823-847 http://doi.org/10.1111/j.1744-6570.1993.tb01571.x <REFJ> Carter, D. R., DeChurch, L. A., Braun, M. T., \& Contractor, N. S. (2015). Social network approaches to leadership: An integrative conceptual review. Journal of Applied Psychology, 100(3), 597-622. http://doi.org/10.1037/a0038922

$<$ REFJ > Carleton, E. L., Barling, J., \& Trivisonno, M. (2018). Leaders' trait mindfulness and transformational leadership: The mediating roles of leaders' positive affect and leadership self-efficacy. Canadian Journal of Behavioural Science/Revue Canadienne des Sciences $d u$ Comportement, 50(3), 185-194. http://doi.org/10.1037/cbs0000103

$<$ REFJ > Chiu, C.-Y. C., Balkundi, P., \& Weinberg, F. J. (2017). When managers become leaders: The role of manager network centralities, social power, and followers' perception of leadership. The Leadership Quarterly, 28(2), 334-348. http://doi.org/10.1016/j.leaqua.2016.05.004

$<$ REFJ $>$ Chiu, S.-F., \& Chen, H.-L. (2005). Relationship between job characteristics and organizational citizenship behavior: The meditational role of job satisfaction. Social Behavior and Personality: An International Journal, 33(6), 523-540. https://doi.org/10.2224/sbp.2005.33.6.523

$<$ REFJ > Cohen, S. G., \& Bailey, D. E. (1997). What makes teams work: Group effectiveness research from the shop floor to the executive suite. Journal of Management, 23(3), 239-290. http://doi.org/10.1016/s0149-2063(97)90034-9 
$<$ REFJ $>$ Curral, L. A., Forrester, R. H., Dawson, J. F., \& West, M. A. (2001). It's what you do and the way that you do it: Team task, team size, and innovation-related group processes. European Journal of Work and Organizational Psychology, 10(2), 187-204. http://doi.org/10.1080/13594320143000627

$\langle\mathrm{REFJ}>$ Festinger, L. (1962). A theory of cognitive dissonance. Stanford University Press.

$<$ REFJ > Flap, H., \& Völker, B. (2001). Goal specific social capital and job satisfaction: Effects of different types of networks on instrumental and social aspects of work. Social Networks, 23(4), 297-320. http://doi.org/10.1016/s0378-8733(01)00044-2

$<$ REFJ> Freeman, L. C. (1979). Centrality in social networks: Conceptual clarification. Social Networks, 1(3), 215-239. http://doi.org/10.1016/0378-8733(78)90021-7

$<$ REFJ $>$ Hackman, J. (1987). The design of work teams. In J. W. Lorsch (Ed.), Handbook of Industrial and Organizational Behavior (pp. 315-342). Prentice-Hall.

$<$ REFJ $>$ Haleblian, J., \& Finkelstein, S. (1993). Top management team size, CEO dominance, and firm performance: The moderating roles of environmental turbulence and discretion. Academy of Management Journal, 36, 844-863. http://doi.org/10.5465/256761

$<$ REFJ> Hayes, A. F. (2009). Beyond Baron and Kenny: Statistical mediation analysis in the new millennium. Communication Monographs, 76(4), 408-420. http://doi.org/10.1080/03637750903310360

$<$ REFJ $>$ Hayes, A. F. (2018). Introduction to mediation, moderation, and conditional process analysis: A regression-based approach ( $2^{\text {nd }}$ Ed.). Guilford Publications.

$<$ REFJ> Hogg, M. A. (1993). Group cohesiveness: A critical review and some new directions. European Review of Social Psychology, 4(1), 85-111. https://doi.org/10.1080/14792779343000031

$<$ REFJ > Hogg, M. A., \& Hains, S. C. (1998). Friendship and group identification: A new look at the role of cohesiveness in groupthink. European Journal of Social Psychology, 28(3), 323-341. https://doi.org/10.1002/(SICI)1099-0992(199805/06)28:3<323::AID-EJSP854>3.0.CO;2-Y

$<$ REFJ $>$ Hoppe, B., \& Reinelt, C. (2010). Social network analysis and the evaluation of leadership networks. The Leadership Quarterly, 21(4), 600-619. http://doi.org/10.1016/j.leaqua.2010.06.004

$<$ REFJ> Judge, T. A., Piccolo, R. F., \& Ilies, R. (2004). The forgotten ones? The validity of consideration and initiating structure in leadership research. Journal of Applied Psychology, 89(1), 36-51. http://doi.org/10.1037/0021-9010.89.1.36

$<$ REFJ $>$ Knoke, D., \& Yang, S. (2008). Social networks analysis ( $2^{\text {nd }}$ Ed.). Sage Publications. http://doi.org/10.4135/9781412985864

$<$ REFJ $>$ Kong, D. T., Konczak, L. J., \& Bottom, W. P. (2015). Team performance as a joint function of team member satisfaction and agreeableness. Small Group Research, 46(2), 160-178. http://doi.org/10.1177/1046496414567684

$\langle$ REFJ $>$ Kwok, N., Hanig, S., Brown, D. J., \& Shen, W. (2018). How leader role identity influences the process of leader emergence: A social network analysis. The Leadership Quarterly, 29(6), 648-662. http://doi.org/10.1016/j.leaqua.2018.04.003

$<$ REFJ > Li, F., Li, Y., \& Wang, E. (2009). Task characteristics and team performance: The mediating effect of team member satisfaction. Social Behavior and Personality: An International Journal, 37(10), 1373-1382. https://doi.org/10.2224/sbp.2009.37.10.1373

$<$ REFJ> Lourenço, P. R., Dimas, I. D., \& Rebelo, T. M. M. S. D. (2014). Effective workgroups: The role of diversity and culture. Revista de Psicología del Trabajo y de las Organizaciones, 30 , 123-132. http://doi.org/10.1016/j.rpto.2014.11.002

$<$ REFJ $>$ Mehra, A., Dixon, A. L., Brass, D. J., \& Robertson, B. (2006). The social network ties of group leaders: Implications for group performance and leader reputation. Organization Science, 17(1), 64-79. http://doi.org/10.1287/orsc.1050.0158

$<$ REFJ> Mehra, A., Kilduff, M., \& Brass, D. J. (2001). The social networks of high and low selfmonitors: Implications for workplace performance. Administrative Science Quarterly, 46(1), 121-146. http://doi.org/10.2307/2667127

$<$ REFJ> Morgeson, F. P., DeRue, D. S., \& Karam, E. P. (2010). Leadership in teams: A functional approach to understanding leadership structures and processes. Journal of Management, 36(1), 5-39. https://doi.org/10.1177/0149206309347376 
<REFJ> Mullen, B., Johnson, C., \& Salas, E. (1991). Effects of communication network structure: Components of positional centrality. Social Networks, 13(2), 169-185. http://doi.org/10.1016/0378-8733(91)90019-p

$<$ REFJ $>$ Nootjarat, R., Chantatub, W., \& Chongstitvatana, P. (2015). The moderating effect of leader centrality on team cohesion and performance in software development projects. International Journal of Business and Information, 10(3), 295-322.

$<$ REFJ $>$ O'Reilly, C. A., Williams, K. Y., \& Barsade, S. (1998). Group demography and innovation: Does diversity help? In M. A. Neale, E. A. Mannix, \& D. H. Gruenfeld (Eds.), Research on managing groups and teams (pp. 183-207). Jai Press.

<REFJ> Park, S., Grosser, T. J., Roebuck, A. A., \& Mathieu, J. E. (2020). Understanding work teams from a network perspective: A review and future research directions. Journal of Management https://doi.org/10.1177/0149206320901573 .

$<$ REFJ $>$ Preacher, K. J., \& Hayes, A. F. (2008). Asymptotic and resampling strategies for assessing and comparing indirect effects in multiple mediator models. Behavior Research Methods, 40(3), 879-891. http://doi.org/10.3758/brm.40.3.879

<REFJ> Ramos-Villagrasa, P. J., Marques-Quinteiro, P., Navarro, J., \& Rico, R. (2018). Teams as complex adaptive systems: Reviewing 17 years of research. Small Group Research, 49(2), 135-176. https://doi.org/10.1177/1046496417713849

<REFJ> Sauer, N. C., \& Kauffeld, S. (2015). The ties of meeting leaders: A social network analysis. Psychology, 6(4), 415-434. http://doi.org/10.4236/psych.2015.64039

$<$ REFJ > Scullen, S. E., Mount, M. K., \& Goff, M. (2000). Understanding the latent structure of job performance ratings. Journal of Applied Psychology, 85(6), 956-970. http://doi.org/10.1037/0021-9010.85.6.956

<REFJ> Tabernero, C., Chambel, M. J., Curral, L., \& Arana, J. M. (2009). The role of task-oriented versus relationship-oriented leadership on normative contract and group performance. Social Behavior and Personality: An International Journal, 37(10), 1391-1404. http://doi.org/10.2224/sbp.2009.37.10.1391

<REFJ> Tse, H. H. M., \& Dasborough, M. T. (2008). A study of exchange and emotions in team member relationships. Group \& Organization Management, 33(2), 194-215. http://doi.org/10.1177/1059601106293779

$<$ REFJ> Uhl-Bien, M., \& Marion, R. (2011). Complexity leadership theory. In A. Bryman, D. Collinson, K. Grint, B. Jackson, \& M. Uhl-Bien (Eds.), The Sage handbook of leadership (pp. 468-482). Sage Publications.

$<$ REFJ > van de Voorde, K., van Veldhoven, M., \& Paauwe, J. (2014). Relationships between work unit climate and labor productivity in the financial sector: A longitudinal test of the mediating role of work satisfaction. European Journal of Work and Organizational Psychology, 23, 295309. https://doi.org/10.1080/1359432X.2012.729312

<REFJ> Venkataramani, V., Zhou, L., Wang, M., Liao, H., \& Shi, J. (2016). Social networks and employee voice: The influence of team members' and team leaders' social network positions on employee voice. Organizational Behavior and Human Decision Processes, 132, 37-48. http://doi.org/10.1016/j.obhdp.2015.12.001

$<$ REFJ> Viswesvaran, C., Ones, D. S., \& Schmidt, F. L. (1996). Comparative analysis of the reliability of job performance ratings. Journal of Applied Psychology, 81(5), 557-574. http://doi.org/10.1037/0021-9010.81.5.557

$<$ REFJ> Wang, Z., Chen, X., \& Yu, M. (2017). Interactive effect of leader-member tie and network centrality on leadership effectiveness. Social Behavior and Personality, 45(7), 1197-1210. http://doi.org/10.2224/sbp.6351

<REFJ> Wasserman, S., \& Faust, K. (1994). Social network analysis: Methods and applications. University Press. http://doi.org/10.1017/CBO9780511815478

<REFJ> Zhao, X., Lynch, J. G., Jr., \& Chen, Q. (2010). Reconsidering Baron and Kenny: Myths and truths about mediation analysis. Journal of Consumer Research, 37(2), 197-206. http://doi.org/10.1086/651257 
Table 1.

Correlation Matrix, Means and Standard Deviations for Study Variables

\begin{tabular}{lccccccc}
\hline Variables & 1. & 2. & 3. & 4. & 5. & 6. & 7. \\
1. Workflow outdegree centrality & -- & & & & & & \\
2. Friendship outdegree centrality & $.35^{* *}$ & --- & & & & & \\
3. Workflow betweenness & $.57^{* * *}$ & .09 & --- & & & & \\
centrality & & & & & & & \\
$\quad$ 4. Friendship betweenness & .23 & $.38^{* *}$ & $.40^{* * *}$ & --- & & & \\
centrality & & & & & & & \\
5. Leader satisfaction with the team & $-.26^{*}$ & .15 & -.04 & .14 & --- & & \\
6. Perception of team performance & -.04 & .22 & .04 & $.28^{*}$ & $.38^{* *}$ & --- & \\
7. Team size & $.68^{* * *}$ & $.24^{*}$ & $.56^{* * *}$ & $.31^{* *}$ & -.19 & .03 & --- \\
\hline$M$ & 3.15 & 1.35 & 3.25 & .81 & 5.59 & 7.48 & 5.30 \\
$S D$ & 2.25 & 1.82 & 6.39 & 2.47 & .83 & .97 & 1.89 \\
\hline
\end{tabular}


Table 2.

Hierarchical Regressions Predicting Leader's Perception of Team Performance from Leader's Outdegree Centrality (Total and Direct Effects)

\begin{tabular}{lccccccc}
\hline & $\mathrm{B}$ & $S E \mathrm{~B}$ & $\beta$ & $t$ & $R^{2}$ & $F$ & $p$ \\
\hline Total effects & & & & & .07 & 1.75 & .16 \\
$\quad$ Team size & 0.05 & 0.08 & .09 & 0.60 & & & .55 \\
Workflow outdegree centrality & -0.08 & 0.07 & -.20 & -1.21 & & .23 \\
$\quad$ Friendship outdegree centrality & 0.14 & 0.07 & .27 & $\mathbf{2 . 1 9}$ & & & .03 \\
\hline Direct effects & & & & & .18 & $\mathbf{3 . 6 8}$ & .01 \\
Team size & 0.05 & 0.08 & .11 & 0.70 & & & .48 \\
Workflow outdegree centrality & -0.04 & 0.07 & -.08 & -0.50 & & .62 \\
Friendship outdegree centrality & 0.09 & 0.06 & .18 & 1.45 & & .15 \\
Leader satisfaction with the team & 0.41 & 0.14 & .35 & $\mathbf{2 . 9 8}$ & & & .001 \\
\hline
\end{tabular}

Note. Values in boldface type are statistically significant $(p<.05) ; p$-values are shown in the table. 
Table 3.

Hierarchical Regression Predicting Leader's Satisfaction from Leader's Outdegree Centrality (Controlling for Team Size)

\begin{tabular}{lccccccc}
\hline & $\mathrm{B}$ & $S E \mathrm{~B}$ & $\beta$ & $t$ & $R^{2}$ & $F(3.70)$ & $p$ \\
\hline & & & & & .13 & $\mathbf{3 . 5 3}$ & .02 \\
Team size & -0.01 & 0.07 & -.03 & -0.20 & & & .84 \\
Workflow outdegree centrality & -0.12 & 0.06 & -.33 & $\mathbf{- 2 . 1 1}$ & & & .04 \\
Friendship outdegree centrality & 0.12 & 0.05 & .27 & $\mathbf{2 . 2 8}$ & & & .03 \\
\hline
\end{tabular}

Note. Values in boldface type are statistically significant $(p<.05) ; p$-values are shown in the table. 
Table 4.

Hierarchical Regressions Predicting Leader's Perception of Team Performance from Leader's Betweenness Centrality (Total and Direct Effects)

\begin{tabular}{lccccccc}
\hline & $\mathrm{B}$ & $S E \mathrm{~B}$ & $\beta$ & $t$ & $R^{2}$ & $F$ & $p$ \\
\hline Total effects & & & & & .08 & 2.12 & .10 \\
$\quad$ Team size & -0.02 & 0.07 & -.04 & -0.29 & & & .77 \\
Workflow betweenness centrality & -0.01 & 0.02 & -.06 & -0.41 & & & .69 \\
Friendship betweenness centrality & 0.12 & 0.05 & .31 & $\mathbf{2 . 5 0}$ & & & .02 \\
\hline Direct effects & & & & & .20 & $\mathbf{4 . 1 9}$ & .001 \\
Team size & 0.03 & 0.07 & .06 & 0.41 & & & .69 \\
Workflow betweenness centrality & -0.01 & 0.02 & -.07 & -0.48 & & .63 \\
Friendship betweenness centrality & 0.09 & 0.05 & .24 & 1.95 & & .06 \\
Leader satisfaction with the team & 0.41 & 0.13 & .35 & $\mathbf{3 . 1 0}$ & & & .00 \\
\hline
\end{tabular}

Note. Values in boldface type are statistical significant $(p<.05) ; p$-values are shown in the table. 
Table 5.

Hierarchical Regression Predicting Leader's Satisfaction from Leader's Betweenness Centrality (Controlling for Team Size)

\begin{tabular}{lccccccc}
\hline & $\mathrm{B}$ & $S E \mathrm{~B}$ & $\beta$ & $t$ & $R^{2}$ & $F(3.70)$ & $p$ \\
\hline & & & & & .08 & 2.11 & .11 \\
Team size & -0.12 & 0.06 & -.27 & -1.96 & & & .05 \\
Workflow betweenness centrality & 0.00 & 0.02 & .02 & 0.14 & & & .89 \\
Friendship betweenness centrality & 0.07 & 0.04 & .22 & 1.75 & & & .08 \\
\hline
\end{tabular}

Note. $p$-values are shown in the table. 
Table 6.

Mediation of Leader's Satisfaction: Unstandardized and Standardized Estimates and Bootstrap Percentile Confidence Intervals for Indirect Effects (Controlling for Team Size)

\begin{tabular}{|c|c|c|c|c|c|c|c|c|}
\hline & \multicolumn{4}{|c|}{ Unstandardized indirect effects } & \multicolumn{4}{|c|}{ Standardized indirect effects } \\
\hline & \multirow[b]{2}{*}{ Estimate } & \multirow[b]{2}{*}{$S E$} & \multicolumn{2}{|c|}{$95 \% \mathrm{CI}$} & \multirow[b]{2}{*}{ Estimate } & \multirow[b]{2}{*}{$S E$} & \multicolumn{2}{|c|}{$95 \% \mathrm{CI}$} \\
\hline & & & $\mathrm{LL}$ & $\mathrm{UL}$ & & & LL & UL \\
\hline \multicolumn{9}{|c|}{ Leader's outdegree centrality } \\
\hline Workflow network & -0.05 & 0.03 & -0.13 & -0.01 & -.12 & .07 & -.28 & -.01 \\
\hline Friendship network & 0.05 & 0.03 & 0.01 & 0.13 & .10 & .06 & .02 & .24 \\
\hline \multicolumn{9}{|c|}{ Leader's betweenness centrality } \\
\hline Workflow network & 0.00 & 0.01 & -0.03 & 0.02 & .01 & .07 & -.17 & .13 \\
\hline Friendship network & 0.03 & 0.02 & 0.01 & 0.10 & .08 & .04 & .02 & .18 \\
\hline
\end{tabular}


Figure 1. Mediation Model with Leader's Outdegree Centrality as Predictor

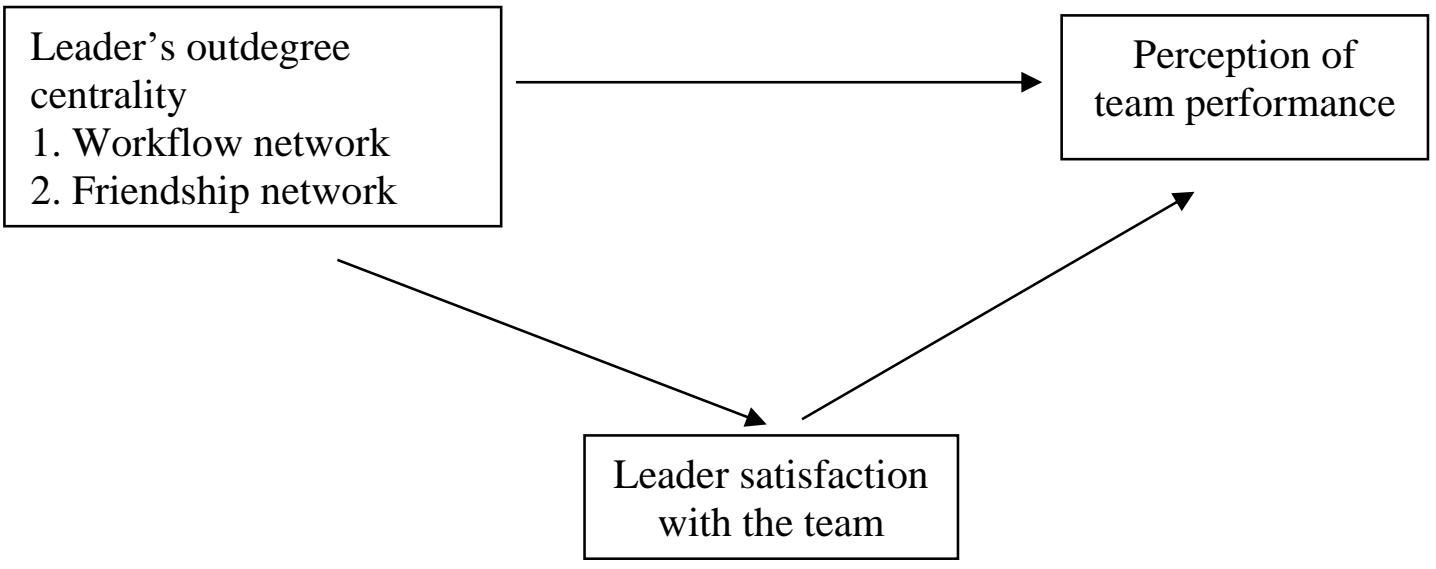


Figure 2. Mediation Model with Leader's Betweenness Centrality as Predictor

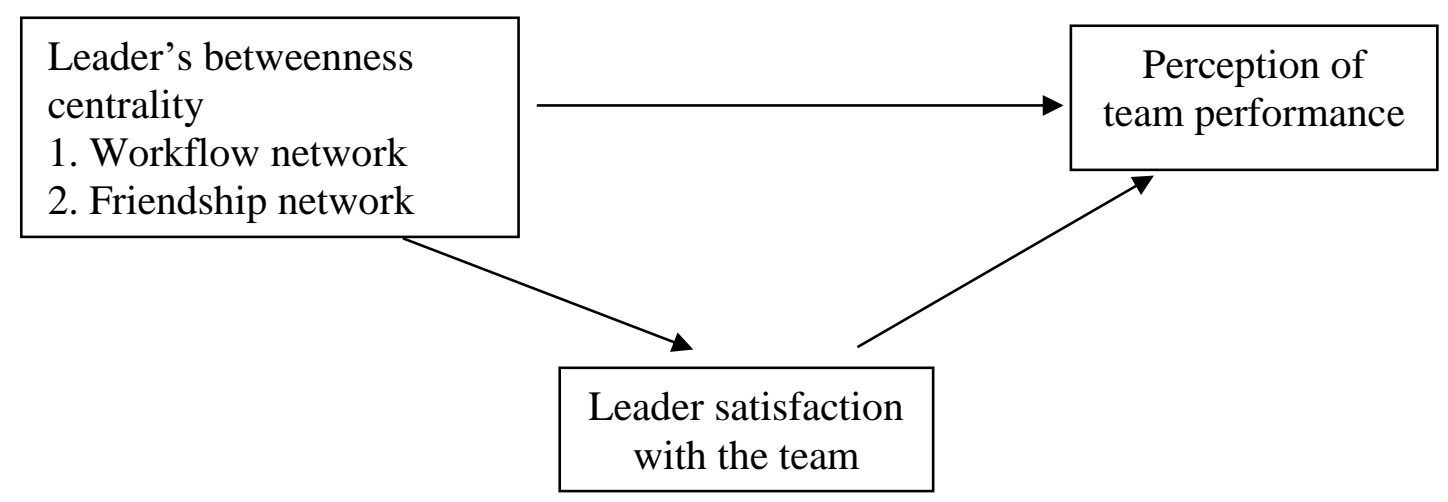




\section{Appendix}

\section{Measures and Items}

\begin{tabular}{ll}
\hline Workflow network & Friendship network \\
\hline I provide ... with the information and & I have a close relationship with ... outside the \\
materials necessary for carrying out his/her & work context. \\
work. & I reveal information about my personal life \\
& to... \\
& I talk about my feelings with ...
\end{tabular}

Leader's satisfaction with the team

Team functioning.

Team climate.

Relationships between team members.

Role that each member has in the team.

Relationship between team members and the leader.

Results achieved by the team.

Perception of team performance

Ability to take a sufficient approach to problems.

Defining strategies with the achievement of fixed goals in mind.

Quality of work produced.

Efficiency in the carrying out of tasks.

Quantity of work produced.

Quality of new ideas/suggestions put forward.

Ability to implement new ideas.

Achieving fixed deadlines.

Number of new ideas/suggestions put forward. 